\title{
Microvesicles and intercellular communication in the context of parasitism
}

\author{
Natasha S. Barteneva ${ }^{1}$, Natalia Maltsev ${ }^{2 *}$ and Ivan A. Vorobjev ${ }^{3,4}$ \\ 1 Program in Cellular and Molecular Medicine, Children's Hospital Boston and Department of Pediatrics, Harvard Medical School, Boston, MA, USA \\ 2 Department of Human Genetics, University of Chicago, Chicago, IL, USA \\ ${ }^{3}$ A.N. Belozersky Institute of Physico-Chemical Biology, Lomonosov Moscow State University, Moscow, Russia \\ ${ }^{4}$ Department of Cell Biology and Histology, Faculty of Biology, Lomonosov Moscow State University, Moscow, Russia
}

\section{Edited by:}

Robert Heinzen, National Institutes

of Health, USA

\section{Reviewed by:}

Stacey Gilk, Indiana University

School of Medicine, USA

Antonio Marcilla, Universitat de

Valencia, Spain

*Correspondence:

Natasha S. Barteneva, Program in Cellular and Molecular Medicine 200 Longwood Avenue, Boston, MA, 02115, USA

e-mail: Natasha.Barteneva@

childrens.harvard.edu;

Natalia Maltsev, Department of

Human Genetics, University of

Chicago, E. 58th str., Chicago,

IL 60637, USA

e-mail:maltsev@uchicago.edu
There is a rapidly growing body of evidence that production of microvesicles (MVs) is a universal feature of cellular life. MVs can incorporate microRNA (miRNA), mRNA, mtDNA, DNA and retrotransposons, camouflage viruses/viral components from immune surveillance, and transfer cargo between cells. These properties make MVs an essential player in intercellular communication. Increasing evidence supports the notion that MVs can also act as long-distance vehicles for RNA molecules and participate in metabolic synchronization and reprogramming eukaryotic cells including stem and germinal cells. MV ability to carry on DNA and their general distribution makes them attractive candidates for horizontal gene transfer, particularly between multi-cellular organisms and their parasites; this suggests important implications for the co-evolution of parasites and their hosts. In this review, we provide current understanding of the roles played by MVs in intracellular pathogens and parasitic infections. We also discuss the possible role of MVs in co-infection and host shifting.

Keywords: microvesicles, exosomes, miRNA, parasite, metabolism synchronization, horizontal gene transfer, co-infection, Plasmodium

\section{INTRODUCTION}

Production of membrane-enclosed microvesicles (MVs) is a universal feature of cellular life and has been demonstrated for organisms as diverse as Proteobacteria, Archaea, plants, and animals (Ellis and Kuehn, 2010; Silverman and Reiner, 2012; Deatherage and Cookson, 2012). Several distinct categories of membraneenclosed MVs exist, including exosomes, ectosomes, and apoptotic bodies (in multi-cellular organisms). MVs are grouped based on their size, density, method of isolation, and markers, and purified MVs usually represent a mixture of aforementioned vesicular fractions.

Secretion of MVs is well-documented for prokaryotic and eukaryotic cells (György et al., 2011; Silverman and Reiner, 2012), and in infected organisms they can contain both host and parasitic antigens. Vesicles from a number of pathogens, such as Leishmania, Cryptococcus, and Trypanosoma, may carry on virulence factors and participate in their delivery to host

\footnotetext{
Abbreviations: 7-AAD, 7-aminoactinomycin D; EAE, experimental allergic encephalomyelitis; EGFP, enhanced green fluorescent protein; GFP, green fluorescent protein; HDM, helminth defense molecules; HDP, host defense peptide; HGT, horizontal gene transfer; LDLRAP1 protein, low density lipoprotein receptor adapter protein; MAPK/ERK pathway, mitogen-activated protein kinases/Extracellular signal-regulated kinases pathway; miRNA, microRNA; mtDNA, mitochondrial DNA; MV, microvesicles; NETs, neutrophil extracellular traps; NETosis, in vivo NETs are released during a form of pathogen-induced cell death, which was recently named NETosis; ORF, open reading frame; PV, parasitophorous vacuole; PVM, parasitophorous vacuole membrane; ROS, reactive oxygen species.
}

cells (Silverman and Reiner, 2011, 2012; Lambertz et al., 2012; Torrecilhas et al., 2012), promoting dissemination of the pathogen.

Though it has become clear that MVs possess immunomodulatory features, little is known about the role of MVs in hostparasite co-existence and co-evolution. We anticipate that recent findings regarding the participation of MVs in the transfer of genetic information will expand the functions attributed to MVs in the host-parasite evolution. We will hypothesize about the role MVs play, as a vehicle for regulatory molecules important for synchronization of host and parasite metabolism, and for delivery of nucleic acids.

\section{MICROVESICLES ARE IMPORTANT INTERCELLULAR COMMUNICATORS}

MVs are considered a universal transport vehicle for intercellular communication. MVs incorporate peptides, proteins, lipids, miRNA, and mRNA, all of which can be transferred and become functional in target cells (Ratajczak et al., 2006; Valadi et al., 2007; Skog et al., 2008; Iglesias et al., 2012). MVs bind to cells through receptor-ligand interactions, fuse with target cell membranes, and deliver their cargo to the cytoplasm of the target cell. As has been observed with tumor-derived MVs, MVs can be enriched in specific coding and non-coding RNAs, chromosomal and mitochondrial DNA, retrotransposon RNA, and Alu transposon elements (Ronquist et al., 2009, 2012; Guescini et al., 2010; Balaj et al., 2011; Rak and Guha, 2012; Waldenstroem et al., 2012). 
Transfer of functional genetic information by MVs was initially shown in the experiments with a reporter mRNA encoding GFP (Deregibus et al., 2007), where intact RNA transcripts capable of serving as templates for protein translation were enriched in shed MVs (Li et al., 2012).

MVs are considered the major "miRNA transporter" between cells, since most extracellular miRNAs are found in vesicles (Gallo et al., 2012; Xu et al., 2013). miRNAs have been identified in helminthes and in protozoa possessing Argonaute/Dicer genes, while they are absent in protozoa lacking enzymes required for RNAi-based interference, such as Plasmodium spp and Cryptosporidium (Baum et al., 2009; Manzano-Roman and SilesLucas, 2012). MV-mediated export of miRNA is selective (Zhang et al., 2010a; Jaiswal et al., 2012; Vickers and Remaley, 2012). mRNA and miRNA packaged in vesicles appear to be more stable and resistant to RNAse digestion in the body fluids, due to the lipid membrane of MVs (Li et al., 2012; Vickers and Remaley, 2012).

During their release, MVs may incorporate components that are originally alien to the cell, such as proteins and nucleic acids that are transiently or constitutively expressed via plasmid or viral vector. Recently, it was shown that exogenous plant miRNA is present in human plasma and animal tissues. These results invoked the idea that miRNAs could regulate gene expression across the kingdoms (Kosaka and Ochiya, 2011; Zhang et al., 2012). We speculate that miRNA derived from the bacterial gut community may be packaged by epithelial cells into MVs and then delivered to different parts of the body, starting with the liver. A recent intriguing finding by two independent groups of the exogenous RNAs of different origin in human plasma samples (Bacteria and Archaea, Fungi, Plants-Wang et al., 2012; microbial RNA sequences-Semenov et al., 2012) supports this assertion.

Overall, MVs as vehicles for miRNA and other regulatory molecules, such as regulatory sequences of mRNA, may play important role in the synchronization of metabolism between the host and its parasites.

\section{MICROVESICLE PROTEOMICS}

The production of MVs rises sharply in many parasitic and infectious diseases (Campos et al., 2010; Barteneva et al., 2013; Table 1). Proteins identified in these MVs were related to vesicle trafficking, signaling molecules and transmembrane small channels and transporters (Rodrigues et al., 2008; Silverman et al., 2010a). We recently showed that significant percentage of proteins identified in MVs during malaria infection belong to classical and alternative complement pathway, components of cytoskeleton, glycolysis and lipid transport (Mantel et al., 2013). Metabolic enzymes related to glycolysis constitute the largest protein family in excretory/secretory proteome of helminth E.caproni (Sotillo et al., 2010). Some glycolytic enzymes in parasitic MVs have separate function that make them important for parasite survival and dissemination (for example, binding of plasminogen for enolase in Leishmania) (Chandra et al., 2010). Furthermore, the MVsproduction may explain the presence of atypical proteins lacking classical secretion signal peptides, like enolase, in the parasite secretions.

Parasite-induced MVs also contain constituent host proteins different depending on the species of parasite. For example, while mucin-2 was found in E. caproni vesicles, only CD19 and the constant region of the IgA heavy chain were found in Fasciola hepatica vesicles (Wilson et al., 2011; Marcilla et al., 2012). Conversely, the same helminth species when develops in several intermediate hosts exhibit host adaptation via differential expression of certain gene families (example: antigen B gene family from E. granulosa) in subsequent life cycle stages (Mamuti et al., 2007; Zhang et al., 2010b), however, no parasite proteomes from MVs produced in different intermediate hosts are currently available. MVs production increased during different developmental stages of parasites and proportion of specific antigens may be changed [as shown for RESA-antigen, during ring-stage, trophozoite and shizont stages of $P$. falciparum development (Natakamol et al., 2011)].

In sum, extracellular MVs contain parasite-specific excretory/secretory proteins (Silverman et al., 2010a; Marcilla et al., 2012), often lacking signal sequences (Leishmania), and participate in delivery of virulence factors and regulation of parasite virulence (Silverman and Reiner, 2011; Torrecilhas et al., 2012). Majority of proteome studies of parasite-produced MVs identified virulence factors in the MVs proteomes (Geiger et al., 2010; Silverman et al., 2010a; Bayer-Santos et al., 2013). MVs deliver virulence factors such as toxins, proteases, adhesins (Amano et al., 2010; Torrecilhas et al., 2012), Entamoeba histolytica rhomboid protease (EhROM1) (Baxt et al., 2008), participate in regulation of gene expression and help to escape immune evasion (Lambertz et al., 2012).

\section{IMMUNOMODULATORY ACTIVITIES OF MICROVESICLES AND MOLECULAR MIMICRY}

Parasites have developed many strategies that support their transmission and allow them to survive and reproduce, such as development of novel cellular pathways that enable invasion into different hosts and diverse immune evasion strategies including: alteration of host antigens, establishment of self-tolerance, functional immune inactivation, immunosuppression, molecular mimicry between parasite polypeptides and host antigens, acquisition of sialic acid motifs from host cells and adsorption of host serum sialoglycoconjugates leading to the modulation of NETosis (Hahn et al., 2013), and antigenic variability regulated by parasite methyltransferases (Figueiredo et al., 2008). Production of MVs appears to be involved in many of these processes.

Molecular mimicry as a strategy for host manipulation and evasion of immune response is well-known in viruses because of their ability to acquire host proteins or genetic material during virion assembly (Alcami, 2003; Bernet et al., 2003). There is significant evidence that autoimmune disease can develop after bacterial or parasitic infection, such as Chagas disease, where a cross-reaction between cardiac muscle cells and T. cruzi occurs (Acosta and Santos-Buch, 1985; Sepulveda et al., 2000). Recently, molecular mimicry between a family of peptides produced by trematode helminthes, and human defense peptides, including defensins and cathelidicins was found (Robinson et al., 2011). This family of helminth defense molecules (HDMs) is conserved 
Table 1 | Microvesicles produced in response to different parasitic pathogens.

\begin{tabular}{llll}
\hline Pathogen & Type of microvesicles (according to publication authors) References
\end{tabular}

\section{FUNGI}

Cryptococcus neoformans Exosomes
Yoneda and Doering, 2006; Rodrigues et al., 2008; Nicola et al., 2009; Panepinto et al., 2009; Oliveira et al., 2010; Huang et al., 2012

Malassezia sympodialis
Paracoccidiodes
Paracoccidiodes brasilensis
PROTOZOA

Exosomes

Gehrmann et al., 2011

Conditioned medium(secreted proteins and vesicles)

Weber et al., 2012

Vallejo et al., 2011, 2012a,b

Giardia lamblia

Secretory vesicles

Leishmania

Exosomes from infected macrophages

Plasma-derived MPs

Plasma-derived MPs (from infected mice)

Vesicles(60-100 nm); microvesicles (100-1000 nm)

Plasmodium falciparum

Plasmodium yoelii

Plasma-derived exosomes

Toxoplasma gondii

Exosomes

Exosomes

Trypanosoma brucei

Outer membrane-derived vesicles, exosomes

Trypanosoma cruzi

\section{MYCOPLASMA}

Mycoplasma

BACTERIA

Borrelia burgdoferi

Brucella abortus

Chlamydia trachomatis

Francisella novacida

Legionella pneumophila

Mycobacterium tuberculosis

Membrane vesicles

Exosomes

Ectosomes (outer membrane vesicles)

Ectosomes (outer membrane vesicles)

Exosomes, outer membrane vesicles

Exosomes; shedding microvesicles

Exosomes

Mycobacterum avium

Exosomes

Mycobacterium bovis

Exosomes

Outer membrane-derived vesicles

Salmonella thyphimurium

HELMINTHS

Caernorhabditis elegans

Echinostoma caproni

Echinococcus multilocularis

Fasciola hepatica
Benchimol, 2004; Gottig et al., 2006

Silverman et al., 2010a,b; Silverman and Reiner, 2011;

Figuera et al., 2012; Hassani and Olivier, 2013

Campos et al., 2010

Combes et al., 2005; Couper et al., 2010

Trelka et al., 2000; Bhattacharjee et al., 2008; Mantel et al., 2013; Regev-Rudzki et al., 2013

Martin-Jaular et al., 2011

Bhatnagar et al., 2007

Geiger et al., 2010

Goncalves et al., 1991; Ouassi et al., 1992; Trocoli

Torrecilhas et al., 2009; Cestari et al., 2012; Bayer-Santos et al., 2013

Quah and O'Neill, 2007; Yang et al., 2012

Toledo et al., 2012

Pollak et al., 2012

Zhong, 2011; Frohlich et al., 2012

Pierson et al., 2011

Galka et al., 2008

Giri et al., 2010; Ramachandra et al., 2010; Singh et al., 2011, 2012; Duarte et al., 2012

Bhatnagar and Schorey, 2007

Giri and Schorey, 2008

Liegeois et al., 2006

Andresen et al., 1989; Marcilla et al., 2012

Eger et al., 2003; Walker et al., 2004; Huebner et al., 2006; Nono et al., 2012

Marcilla et al., 2012
Yoon et al., 2011 
throughout trematodes, and these proteins participate in the host immune response modulation and anti-inflammatory action (Robinson et al., 2011).

Infections caused by intracellular pathogens and parasites are often chronic and lead to significant immunomodulation of host immune response by the parasite. MVs produced during protozoan infections were shown to participate in this process (Bhatnagar and Schorey, 2007; Bhatnagar et al., 2007; Barreto et al., 2010; Silverman et al., 2010a; Hassani and Olivier, 2013). For example, during Plasmodium infection, there are increased quantities of MVs in plasma, and they contain a significant amount of parasite material. These MVs induce neutrophil activation (Mantel et al., 2013) and strong pro-inflammatory activation of macrophages as measured by CD40 and TNF up-regulation (Couper et al., 2010). Besides, vesiculation, which utilizes host cell machinery, is an important mechanism for parasite egress in the case of $P$. falciparum, the cause of malaria and a member of the phylum Apicomplexa (Lew, 2011). Secreted vesicles, which in the case of helminthes, present among other parasite secretion products, have been shown to modulate host immune responses and strongly influence the outcome of infections to the parasite's advantage (Spolski et al., 2000; Allen and MacDonald, 1998; Silverman et al., 2010b).

In our recent publication more than thirty parasite proteins in MVs derived from red blood cells infected with 3D7 or CS2 strains of $P$. falciparum were identified (Mantel et al., 2013). A modified approach, first described by Ludin et al. (2011) was employed, allowing for rigorous analysis of $P$. falciparum proteins that may potentially contribute to the infectious process via molecular mimicry of host molecules. Identified potential candidates include erythrocyte-binding proteins 1, 2, and 3, liver-stage antigen, and others (e.g., Rex2) (manuscript in preparation). Figures 1A-C shows the similarity between the $P$. falciparum short (119 amino acids) PEXEL (Plasmodium export element)negative ring-exported protein $2(\operatorname{Rex} 2)$ and the $H$. sapiens $\mathrm{Rac} 1$ and Rac2 proteins, providing one example of possible molecular mimicry and parasite-human HGT in parasitic invasion (Figure 1D). It was previously demonstrated (Haase et al., 2009) that a short sequence in the N-terminus and transmembrane domain of the Rex 2 protein are both required for parasite export. The N-terminus of Rex2 exhibits significant similarity to the human small GTP-ases Rac1 and Rac2. A number of studies have demonstrated that deleterious mutations in Rac2 lead to defective chemotaxis, impaired phagocytosis, and decreased pathogen killing by macrophages and/or neutrophils (Roberts et al., 1999; Koh et al., 2005; Yamauchi et al., 2005; Zhang et al., 2009). Because it has been reported that neutrophils from malaria patients have reduced chemotactic activity (Nielsen et al., 1986; Leoratti et al., 2012), a role for Rex2 in molecular mimicry of Rac2 is likely. It is anticipated that in silico analysis of other pathogen-derived MV-associated proteins will be helpful in further understanding how MVs function as intercellular communicators during disease states, and provide insights on what to base future experimental studies on.

Molecular mimicry may be a more prevalent parasitic strategy than was previously thought (Ludin et al., 2011). Acquisition of complete nucleotide sequences or sequence motifs from the host may happen at different stages of parasite-host co-existence, and MVs may play a significant role in this molecular exchange.

\section{DO MICROVESICLES PARTICIPATE IN CO-INFECTION?}

Parasitic and symbiotic associations are ubiquitous and often lifelong relationships (Eckburg et al., 2005; Weiss and Aksoy, 2011). Every mammal possesses complex microbial communities that reside on all mucosal surfaces. The human gastrointestinal tract harbors an estimated 1014 species of microbes from over 500 distinct microbial taxa (Eckburg et al., 2005). Although infectious parasite biology research is still dominated by studies of single infections poly-parasitism is very common in nature (Petney and Andrews, 1998; Bordes and Morand, 2009). Infection with one parasitic species can have a large impact on host susceptibility to secondary infection, and this phenomenon is partially dependent on the duration of infection (Telfer et al., 2010).

There is a growing body of evidence that concurrent parasitic infections can confer benefits to their hosts. For example, Wolbachia, which is considered a reproductive parasite in arthropods (Werren et al., 2008), can provide metabolic advantages to their hosts during stressful conditions, such as increased haem and riboflavin availability (Brownlie et al., 2009; Hosokawa et al., 2010). There are a number of studies outlining associations between different parasitic co-infections. Thus, helminth infection can prevent or suppress autoimmune and allergic diseases depending on helminth burden (reviewed in Zaccone and Cooke, 2013). A similar finding has been described for malaria infection, where the disease can be asymptomatic or less severe, with concomitant lower parasitaemia, in helminth-infected patients (Adegnica and Kremsner, 2012). The infection of Schistosoma haematobium is associated with protection against acute $P$. falciparum infection (Lyke et al., 2005).

The role of MVs as messengers between parasite and host immune cells is well-established (Silverman and Reiner, 2012). We have shown involvement of MVs in cross-communication within a $P$. falciparum population (Mantel et al., 2013). The exchange of MVs derived from different parasites as well as from host cells can participate in the mechanisms of co-infection (Figure 1E). However, there are currently no published reports describing the communication of MVs derived from different parasites and the issue deserves in-depth elucidation.

\section{SEARCHING FOR NEW CLUES IN INTERCELLULAR COMMUNICATION BY IN SILICO GENOMICS AND PROTEOMICS}

Amoebae, as well as other free-living protozoan hosts for bacteria, fungi, giant DNA viruses and virophages are "melting pots" for HGT exchanges (Hotopp et al., 2007; Moliner et al., 2010; Raoult and Boyer, 2010; Lamrabet et al., 2012). Besides, DNA exchange may also occur in reverse from microorganisms to protozoa (Ricard et al., 2006), and to animals (McNulty et al., 2010; Dunning Hotopp, 2011). Examples of gene transfer from the animal host to the ancestor of the apicomplexan parasites include genes encoding proteins involved in cell adhesion, O-linked glycosylation and a major epigenetic regulator histone methyltransferase Set8 (Kishore et al., 2013). In many instances, interdomain HGT involves transfers between endosymbiotic bacteria and their 


\section{A}

RAC2_HUMAN RAC1_HUMAN Q8I2GO_Rex2

RAC2_HUMAN RAC1_HUMAN Q8I2G0_Rex2

\section{RAC2_HUMAN} RAC1_HUMAN Q8I2GO_Rex2
MQAIKCVVVGDGAVGKTCLIISYTTNAFPGEYIPTVEDNYSANVMVDSKPVNLGLWDTAG 60 MQAIKCVVVGDGAVGKTCLLISYTTNAFPGEYIPTVFDNYSANVMVDGKPVNLGLWDTAG 60 MKMYLAEIFSSGKESLLSLKDTLG 24

QEDYDRLRPLS----YPQTDVFLICFSLVSPASYENVRARWFPEVRHHCPSTPIILVGTK 116 QEDYDRLRPLS----YPQTDVELICFSLVSPASFENVRAKWYPEVRHHCPNTPIILVGTK 116 SSNFSPLKPCEGLECLPQVLFL YUIFLLLCTGIFMHNKNKEHHHEKSHNNGQNSNUPKNS 84

$\cdots: 2 * z^{*}$

LDLRDDKDTIEKLKEKKLLAPITYPQGLALAKEIDSVKYLECSALTQRGLKTVFDEAIRAV 176 LDLRDDKDTIEKLKEKKLTPITYPQGLAMAKBIGAVKYLECSALTQRGLKTVFDEAIRAV 176 FQNNKSQNHVQKSKVENQKVPVAQGSQHKSAAVNA_-_ 119

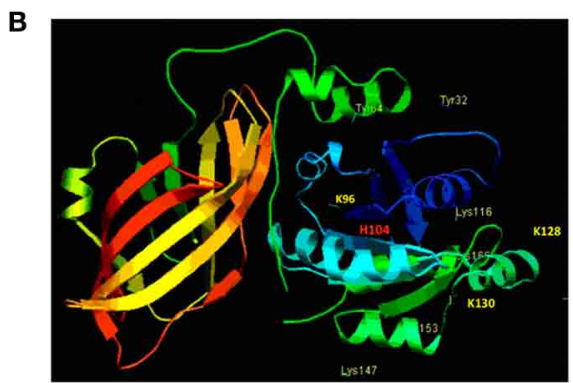

1 DS6 -- Rac2 (Human)

C
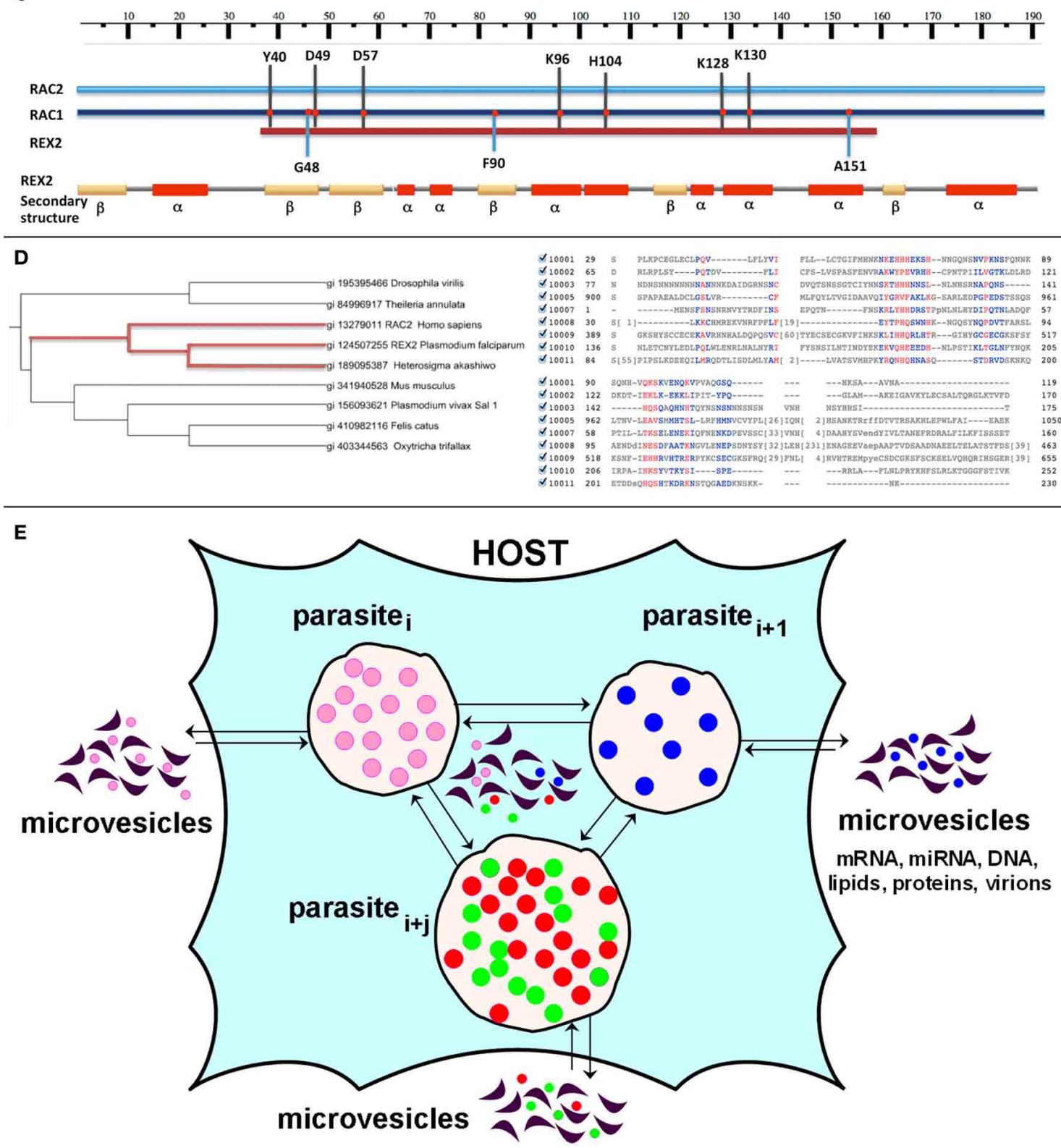

FIGURE 1 | Alignment and PSI-Blast analysis of Rex2 P falciparum protein. (A) ClustalW sequence alignment of Rex2 P. falciparum protein (NCBI accession XP_001352224; Uniprot ID Q8I2GO_PLAF7) with Human Rac1 protein (NCBI accession AAH04247; Uniprot ID RAC1_HUMAN) and Ras-related C3 botulinum toxin substrate 2 RAC2_HUMAN. As follows from the alignment $(\mathbf{A})$ the $\mathrm{N}$-terminus of the $P$. falciparum Rex2 protein shares significant similarity with the Rac1 and Rac2 proteins. In the active GTP-bound state these proteins regulate a variety of cellular responses, such as secretory processes, phagocytosis of apoptotic

(Continued) 


\section{FIGURE 1 | Continued}

cells, and epithelial cell polarization. Rac2 activity also includes regulation of human neutrophil NADPH oxidase and activation of the production of reactive oxygen species (ROS). (B) Three-dimensional structure of human Rac2 (critical aminoacids are shown with numbers). (C) Sequence alignment between $P$. falciparum Rex2 and Rac2 and Rac1 proteins reveals an exact match in a number of functionally important amino acids positions, including (a) Asp57. RAC2 Asp57Asn mutation has been shown to be associated with severely impaired fMLP- or IL-8-induced neutrophil responsiveness, including adhesion, chemotaxis, and superoxide production. The Asp57-mutant Rac2 does not bind GTP and was found to act in a dominant-negative fashion for both Rac1 and Rac2 because of its tight GEF binding; (b) $\mathrm{H} 103$, which is involved in Rac1-mediated oxidase activation, and (c) the ubiquitination sites K96 and K123. The alignment also revealed exact matches found exclusively between the Rac1 and Rex2 proteins, including G48, F90 and A151. However, the functional impact of these amino acids is not yet known. (D) PSI-Blast analysis of Plasmodium falciparum 3D7 Rex2 protein against NCBI non-redundant database showed weak similarities to hypothetical proteins from parasitic Apicomplexa Theileria annulata, ciliate Protozoa Oxytricha trifallax, Felis catus (gi410982116), Drosophila virilis (gi195395466), as well as mouse Nrde2 protein (gi|19344080). Multiple sequence alignment of these proteins was developed using NCBI Cobalt (Papadopoulos and Agarwala, 2007). Maximum likelihood phylogenetic tree was developed using the iTOL server and default parameters (Letunic and Bork, 2011). As it follows from the tree the Rex2 protein most closely evolutionary relates to a hypothetical protein from algae Heterosigma akashiwo and Human Rac2 protein. Evolutionary relations between algae and Apicomplexa are well-established (Lemgruber et al., 2013), however, relatedness to Human Rac2 protein suggests HGT from parasite to Human. (E) A hypothetical scheme of MVs exchange in parasite-host interaction. Host and multiple parasites produce and exchange microvesicles, which transfer lipids, proteins, nucleic acids such as miRNA, mRNA, DNA, and may camouflage virions. hosts and from bacteria to asexual animals (Dunning Hotopp, 2011). For example, Wolbachia-to-arthropod HGT has been seen in the genomes of the bean beetle (Coleoptera) (Kondo et al., 2002), mosquitoes (Diptera) (Klasson et al., 2009; Woolfit et al., 2009), and other arthropods, as well as HGT in the opposite direction-from arthropod to Wolbachia (Duplouy et al., 2013). Some Microsporidia species acquired a gene from arthropods that encodes purine nucleotide phosphatase, though most HGT to Microsporidia identified to date derives from prokaryotes (Selman and Corradi, 2011).

Analysis of T. cruzi ribosomal proteins in silico identified significant homology not only with members of the animal kingdom (H. sapiens, C. elegans, D. melanogaster), but also with plants and protozoa (Wayengera, 2009). Recent massive bioinformatics analyses of whole genome sequences have shown that many intracellular prokaryotes have the ability to manipulate the eukaryotic ubiquitin system through molecular mimicry of the F-box component of the SCF E3-ubiquitin ligase eukaryotic-like F-box proteins (Price et al., 2009; Price and Kwaik, 2010).

The ability of MVs to serve as vehicles not only for proteins and lipids, but also for nucleic acids (Ronquist et al., 2009, 2012; Guescini et al., 2010; Balaj et al., 2011; Pisetsky et al., 2011; Rak and Guha, 2012), make us hypothesize that MV production and exchange are an important mechanisms in gene information exchange between parasites and their hosts. As described above, this is indirectly confirmed by a number of similarities between parasite protein sequences and host molecules. Recent studies of mammalian (equine) ovarian follicles revealed that intercellular communication in the ovarian follicle may involve transfer of miRNA and other bioactive molecules by MVs between follicular fluid and granulosa cells (da Silveira et al., 2012). In addition, the transfer of chromosomal DNA fragments by prostate-derived MVs to human sperm (vertical transfer) was described by Ronquist et al. (2009). Moreover, MVs camouflage viruses from immune surveillance and facilitate their access to cells (Kadiu et al., 2012).

Thus, we hypothesize that one of the important functions of MVs in parasite-host and parasite-parasite co-evolution is their participation in HGT. This hypothesis is based on the following properties of MVs: (1) the ability to transfer nucleic acids, including DNA; (2) the capability of MVs to protect and deliver genetic information to different organs, including reproductive organs in the case of multi-cellular organisms; and (3) the ability to transfer cargo to alien cells and tissues (in the case of parasites). Regev-Rudzki et al. (2013) recently provided additional support to this hypothesis confirming that $P$. falciparum derived MVs are capable of delivering genes between parasite populations inside their host.

\section{CONCLUDING REMARKS}

MVs are emerging as critical players in HGT including small noncoding RNAs. Major challenges in the field of extracellular vesicle research include (1) development of new comprehensive methods for their isolation and characterization, and (2) isolation of pure populations of specific MVs. Improved understanding of the mechanisms involved in vesicle shuttling of genetic information and proteins is crucial in order for new diagnostic and therapeutic strategies to be designed and implemented.

Dissemination of parasite components with MVs provides (1) a unique advantage in protection against host-mediated immune responses and nucleases from blood and other body fluids, (2) the possibility of reaching distant regions and evading immune attacks due to their small size $(<1 \mu \mathrm{m})$, and (3) the capability of transferring genetic information long-distance-this may lead to direct participation of pathogenic components in the regulation of gene expression in the different host cells and metabolism synchronization between host and parasite, as well as HGT. This may contribute to further co-adaptation and co-evolution of the parasite and its host. Remarkably, MV exchange may happen similarly in dramatically different animal host cells, as well as in simple multicellular organisms. This can lead to broader host ranges and an increase in the virulence of certain parasites.

Our present knowledge of MVs derived from parasites comes from studies involving limited numbers of parasites and hosts. In the future our understanding of how parasite-host exchange of regulatory molecules and genetic information happens may change, especially when taking into account interactions between multiple parasitic species within the same host organism.

\section{ACKNOWLEDGMENTS}

We are thankful to Dr. Luke Jasenosky for critical reading and Aleksandra Gorelova (Harvard University) for editorial 
help. Natasha S. Barteneva was supported by Harvard Pilot Grant and Program in Cellular and Molecular Medicine, and Ivan A. Vorobjev was supported by Russian Foundation for Basic Research grants 11-04-01749a and 13-04-40189H. Natalia

\section{REFERENCES}

Acosta, A. M., and Santos-Buch, C. A. (1985). Autoimmune myocarditis induced by Trypanosoma cruzi. Circulation 71, 1255-1261. doi: 10.1161+/01.CIR.71.6.1255

Adegnica, A. A., and Kremsner, P. G. (2012). Epidemiology of malaria and helminth interaction: a review from 2001 to 2011. Curr. Opin. HIV AIDS 7, 221-224. doi: 10.1097/COH.0b013e3283524d90

Alcami, A. (2003). Viral mimicry of cytokines, chemokines and their receptors. Nat. Rev. Immunol. 3, 36-50. doi: 10.1038/nri980

Allen, J. E., and MacDonald, A. S. (1998). Profound suppression of cellular proliferation mediated by the secretions of nematodes. Parasite Immunol. 20, 241-247. doi: 10.1046/j.1365-3024.1998.00151.x

Amano, A., Takeuchi, H., and Furuta, N. (2010). Outer membrane vesicles function as offensive weapons in host-parasite interactions. Microbes Infect. 12, 791-798. doi: 10.1016/j.micinf.2010.05.008

Andresen, K., Simonsen, P. E., Andersen, B. J., and BirchAndersen, A. (1989). Echinostoma caproni in mice: shedding of antigens from the surface of an intestinal trematode. Int. J. Parasitol. 19, 111-118. doi: 10.1016/ 0020-7519(89)90028-3

Balaj, L., Lessard, R., Dai, L., Cho, Y.-J., Pomeroy, S. L., Breakefield, X. O., et al. (2011). Tumour microvesicles contain retrotransposon elements and amplified oncogene sequences. Nat. Commun. 2, 180. doi: $10.1038 /$ ncomms 1180

Barreto, A., Rodriguez, L. S., Rojas, O. L., Wolf, M., Greenberg, H. B., Franco, M. A., et al. (2010). Membrane vesicles released by intestinal epithelial cells infected with rotavirus inhibit T-cell function. Viral Immunol. 23, 595-608. doi: 10.1089/vim.2009.0113

Barteneva, N. S., Fasler-Kan, E., Bernimoulin, M., Stern, J. N., Ponomarev, E. D., Duckett, L., et al. (2013). Circulating microparticles: square the circle. BMC Cell Biol. 14:23. doi: 10.1186/1471-2121-1423

Baum, J., Papenfuss, A. T., Mair, G. R., Janse, C. J., Vlachou, D., Waters, A. P., et al. (2009). Molecular genetics and comparative genomics reveal RNAi is not functional in malaria parasites. Nucleic Acids Res. 37, 3788-3798. doi: 10.1093/nar/gkp239

Baxt, L. A., Baker, R. P., Singh, U., and Urban, S. (2008). An Entamoeba atypical specificity cleaves a surface lectin involved in phagocytosis and immune evasion. Genes Dev. 22, 1636-1646. doi: 10.1101/gad. 1667708

Bayer-Santos, E., Aguilar-Bonavides, C., Rodrigues, S. P., Cordero, E. M., Margues, A. F., Varela-Ramirez, A., et al. (2013). Proteomic analysis of Trypanosoma cruzi secretome: characterization of two populations of extracellular vesicles and soluble proteins. J. Proteome Res. 12, 883-897. doi: 10.1021/pr300947g

Benchimol, M. (2004). The release of secretory vesicle in encysting Giardia lamblia. FEMS Microbiol. Lett. 235, 81-87. doi: 10.1111/j. 1574-6968.2004.tb09570.x

Bernet, J., Mullick, J., Singh, A. K., and Sahu, A. (2003). Viral mimicry of the complement system. J. Biosci. 28, 249-264. doi: 10.1007/BF02970145

Bhatnagar, S., and Schorey, J. S. (2007). Exosomes released from infected macrophages contain Mycobacterium avium glycopeptiJ. Biol. Chem. 282, 25779-25789. doi: 10.1074/jbc.M702277200

Bhatnagar, S., Shinagawa, K. Castellino, F. J., and Schorey, J. S. (2007). Exosomes released intracellular pathogens stimulate a proinflammatory response in vitro and in vivo. Blood 110 , 3234-3244. doi: 10.1182/blood2007-03-079152

Bhattacharjee, S., van Ooij, C., Balu, B., Adams, J. H., and Haldar, K. (2008). Maurer's clefts of Plasmodium falciparum are secretory organelles that concentrate virulence protein reporters for delivery to the host erythrocyte. Blood 111, 2418-2426. doi: 10.1182/blood2007-09-115279

Bordes, F., and Morand, S. (2009). Coevolution between multiple helminth infestations and basal immune investment in mammals: histolytica rhomboid protease with dolipids and are proinflammatory. from macrophages infected with

Maltsev is grateful to Mr. and Ms. Lawrence Hilibrand and the Boler Family Foundation for their generous support of the project. Space considerations limited us to a selected list of available literature.

cumulative effects of polyparasitism. Parasitol. Res. 106, 33-37. doi: 10.1007/s00436-009-1623-6

Brownlie, J. C., Cass, B. N., Riegler, M., Witsenburg, J. J., Iturbe-Ormaetxe, I., McGraw, E. A., et al. (2009). Evidence for metabolic provisioning by a common invertebrate endosymbiont, Wolbachia pipientis, during periods of nutritional stress. PLoS Pathog. 5:e1000368. doi: 10.1371/journal.ppat. 1000368

Campos, F. M. F., Franklin, B. S., Teixeira-Carvalho, A., Filho, A. L. S., de Paula, S., Fontes, C. J., et al. (2010). Augmented plasma microparticles during acute Plasmodium vivax infection. Malar J. 9:327. doi: 10.1186/1475-28759-327

Cestari, I., Ansa-Addo, E., Deolindo, P., Inal, J. M., and Ramirez, M. I. (2012). Trypanosoma cruzi immune evasion mediated by host cellderived microvesicles. J. Immunol. 188, 1942-1952. doi: 10.4049/jimmunol.1102053

Chandra, S., Ruhela, D., Deb, A., and Vishwakarma, R. A. (2010). Glycobiology of the Leishmania parasite and emerging targets for antileishmanial drug discovery. Expert Opin. Ther. Targets 14, 739-757. doi: 10.1517/14728222.2010.495125

Combes, V., Coltel, N., Alibert, M., van Eck, M., Raymond, C., JuhanVague, I., et al. (2005). ABCA1 gene deletion protects against cerebral malaria. Potential pathogenic role of microparticles in neuropathology. Am. J. Pathol. 166, 295-302. doi: 10.1016/S0002-9440 (10)62253-5

Couper, K. N., Barnes, T., Hafalla, J. C. R., Combes, V., Ryffel, B., Secher, T., et al. (2010). Parasite-derived plasma microparticles contribute significantly to malaria infectioninduced inflammation through potent macrophage stimulation. PLoS Pathog. 6:e1000744. doi: 10.1371/journal.ppat.1000744

da Silveira, J. C., Veeramachasneni, D. N., Winger, Q. A., Carnevale, E. M., and Bouma, G. J. (2012). Cellsecreted vesicles in equine ovarian follicular fluid contain miRNAs and proteins: a possible new form of cell communication within the ovarian follicle. Biol. Reprod. 86, 71. doi: 10.1095/biolreprod.111.093252
Deatherage, B. L., and Cookson, B. T. (2012). Membrane vesicle release in bacteria, eukaryotes, and archea: a conserved yet underappreciated aspect of microbial life. Infect. Immun. 80, 1948-1957. doi: 10.1128/IAI.06014-11

Deregibus, M. C., Cantaluppi, V., Calogero, R., Lo Iacono, M., Tetta, C., Biancone, L., et al. (2007). Endothelial progenitor cell derived microvesicles activate an angiogenic program in endothelial cells by a horizontal transfer of mRNA. Blood 110, 2440-2448. doi: 10.1182/blood-2007-03-078709

Duarte, T. A., Noronha-Dutra, A. A., Nery, J. S., Ribeiro, S. B., Pitanga, T. N., Lapa E Silva, J. R., et al. (2012). Mycobacterium tuberculosis-induced neutrophil ectosomes decrease macrophage activation. Tuberculosis (Edinb) 92, 218-225. doi: 10.1016/j.tube.2012. 02.007

Dunning Hotopp, J. C. (2011). Horizontal gene transfer between bacteria and animals. Trends Genet. 27, 157-163. doi: 10.1016/j.tig.2011.01.005

Duplouy, A., Iturbe-Ormaetxe, I., Beatson, S. A., Szaubert, J. M., Brownlie, J. C., McMeniman, C. J., et al. (2013). Draft genome sequence of the male-killing Wolbachia strain wBoll reveals recent horizontal gene transfer from diverse sources. BMC Genomics 14:20. doi: 10.1186/1471-216414-20

Eckburg, P. B., Bik, E. M., Bernstein, C. N., Purdom, E., Dethlefsen, L., Sargent, M., et al. (2005). Diversity of the human intestinal microbial flora. Science 308, 1635-1638. doi: 10.1126/science. 1110591

Eger, A., Kirch, A., Manfras, B., Kern, P., Schulz-Key, H., and Soboslay, P. T. (2003). Pro-inflammatory (IL-1 beta, IL-18) cytokines and IL-8 chemokine release by PBMC in response to Echninococcus multiocularis metacestode vesicles. Parasite Immunol. 25 103-105. doi: 10.1046/j.13653024.2003.00601.x

Ellis, T. N., and Kuehn, M. J. (2010). Virulence and immunomodulatory roles of bacterial outer membrane vesicles. Microbiol. Rev. 74, 81-94. doi: 10.1128/MMBR.00031-09 
Figueiredo, L. M., Janzen, C. J., and Cross, G. A. (2008). A histone methyltransferase modulates antigenic variation in African trypanosomes. PLoS Biol. 6:e161. doi: 10.1371/journal.pbio.0060161

Figuera, L., Acosta, H., GomezArreaza, A., Davila-Vera, D., Balza-Quintero, A., Quinones, W., et al. (2012). Plasminogen binding proteins in secreted membrane vesicles of Leishmania mexicana. Mol. Biochem. Parasitol. 187, 14-20. doi: 10.1016/j.molbiopara. 2012.11.002

Frohlich, K., Hua, Z., Wang, J., and Shen, L. (2012). Isolation of Chlamydia trachomatis and membrane vesicles derived from host and bacteria. J. Microb. Methods 91, 222-230. doi: 10.1016/j.mimet. 2012.08.012

Galka, F., Wai, S. N., Kusch, H., Engelmann, S., Hecker, M., Schmeck, B., et al. (2008). Proteomic characterization of the whole secretome of Legionella pneumophila and functional analysis of outer membrane vesicles. Infect. Immun. 76, 1825-1836. doi: 10.1128/IAI.01396-07

Gallo, A., Tandon, M., Alevizos, I., and Illei, G. G. (2012). The majority of microRNAs detectable in serum and saliva is concentrated in exosomes. PLoS ONE 7:e30679. doi: 10.1371/journal. pone. 0030679

Gehrmann, U., Qazi, K. R., Johansson, C., Hultenby, K., Karlsson, M., Lundeberg, L., et al. (2011). Nanovesicles from Malassezia sympodialis and host exosomes induce cytokine responses-novel mechanisms for host-microbe interactions in atopic eczema. PLOS ONE 6:e21480. doi: 10.1371/ journal.pone.0021480

Geiger, A., Hirtz, C., Becue, T., Bellard, E., Centeno, D., Gargani, D., et al. (2010). Exocytosis and protein secretion in Trypanosoma. BMC Microbiol. 10:20. doi: 10.1186/1471-2180-10-20

Giri, P. K., Kruh, N. A., Dobos, K. M., and Schorey, J. S. (2010). Proteomic analysis identifies highly antigenic proteins in exosomes from M.tuberculosis-infected and culture filtrate protein-treated macrophages. Proteomics 10 , 3190-3202. doi: 10.1002/pmic.200 900840

Giri, P. K., and Schorey, J. S. (2008). Exosomes derived from M.bovis BCG infected macrophages activate antigen-specific $\mathrm{CD} 4^{+}$- and $\mathrm{CD} 8^{+}$T-cells in vitro and in vivo. PLoS
ONE 3:e2461. doi: 10.1371/journal.pone. 0002461

Goncalves, M. F., Umezawa, E. S., Katzin, A. M., de Souza, W., Alves, M. J. M., Zingales, B., et al. (1991). Trypanosoma cruzi: shedding of surface antigens as membrane vesicles. Exp. Parasitol. 72, 43-53. doi: 10.1016/0014-4894(91) 90119-H

Gottig, N., Elias, E. V., Quiroga, R., Nores, M. J., Solari, A. J., Touz, M. C., et al. (2006). Active and passive mechanisms drive secretory granule biogenesis during differentiation of the intestinal parasite Giardia lamblia. J. Biol. Chem. 281, 18156-18166. doi: 10.1074/jbc.M602081200

Guescini, M., Genedani, S., Stocchi, V., and Agnati, L. F. (2010). Astrocytes and glioblastoma cells release exosomes carrying mtDNA. J. Neural. Transm. 117, 1-4. doi: 10.1007/s00702-009-0288-8

György, B., Szabó, T. G., Pásztói, M., Pál, Z., Misják, P., Aradi, B., et al. (2011). Membrane vesicles, current state-of-the-art: emerging role of extracellular vesicles. Cell. Mol. Life Sci. 68, 2667-2688. doi: 10.1007/s00018-011-0689-3

Haase, S., Herrmann, S., Gruering, C., Heiber, A., Jansen, P. W., Langer, C., et al. (2009). Sequence requirements for the export of the Plasmodium falciparum Maurer's clefts protein REX2. Mol. Microbiol. 71, 1003-1017. doi: 10.1111/j.1365-2958.2008.06582.x

Hahn, S., Giaglis, S., Chowdhury, C. S., Hoesli, I., and Hasler, P. (2013). Modulation of neutrophil NETosis: interplay between infectious agents and underlying host physiology. Semin. Immunopathol. 35, 439-453. doi: 10.1007/s00281-0130380-x

Hassani, K., and Olivier, M. (2013). Immunomodulatory impact of Leishmania-induced macrophage exosomes: a comparative proteomic and functional analysis. PLoS Negl. Trop. Dis. 7:e2185. doi: 10.1371/journal.pntd.0002185

Hosokawa, T., Koga, R., Kikuchi, Y., Meng, X. Y., and Fukatsu, T. (2010). Wolbachia as a bacteriocyteassociated nutritional mutualist. Proc. Natl. Acad. Sci. U.S.A. 107, 769-774. doi: 10.1073/pnas.091147 6107

Hotopp, J. C., Clark, M. E., Oliveira, D. C., Foster, J. M., Fischer, P., Munoz-Torres, M. C., et al. (2007). Widespread lateral gene transfer from intracellular bacteria to multicellular eukaryotes.
Science 317, 1753-1756. doi: 10.1126/science. 1142490

Huang, S. H., Wu, C. H., Chang, Y. C., Kwon-Chung, K. J., Brown, R. J., and Jong, A. (2012). Cryptococcus neoformans-derived microvesicles enhance the pathogenesis of fungal brain infection. PLoS ONE 7:e48570. doi: 10.1371/journal pone. 0048570

Huebner, M. P., Manfras, B. J., Margos, M. C., Eiffler, D., Hoffmann, W. H., Schulz-Key, H., et al. (2006). Echinococcus multiocularis metacestodes modulate cellular and chemokine release by peripheral blood mononuclear cells in alveolar echinococcosis patients. Clin. Exp. Immunol. 145, 243-251. doi: 10.1111/j.1365-2249. 2006.03142.x

Iglesias, D. M., El-Kares, R., Taranta, A., Bellomo, F., Emma, F., Besouw, M. et al. (2012). Stem cell microvesicles transfer cystinosin to human cystinotic cells and reduce cystine accumulation in vitro. PLoS ONE 7:e42840. doi: 10.1371/journal.pone. 0042840

Jaiswal, R., Luk, F., Gong, J., Mathys, J. M., Grau, G. E., and Bebawy, M. (2012). Microparticle conferred microRNA profiles - implications in the transfer and dominance of cancer traits. Mol. Cancer 11:37. doi 10.1186/1476-4598-11-37

Kadiu, I., Narayanasamy, P., Dash, P. K., Zhang, W., and Gendelman, H. E. (2012). Biochemical and biologic characterization of exosomes and microvesicles as facilitators of HIV-1 infection in macrophages. J. Immunol. 189, 744-754. doi: 10.4049/jimmunol. 1102244

Kishore, S. P., Stiller, J. W., and Deitsch, K. W. (2013). Horizontal transfer of epigenetic machinery and evolution of the parasitism in the malaria parasite Plasmodium falciparum and other apicomplexans. BMC Evol. Biol. 13:37. doi: 10.1186/1471-214813-37

Klasson, L., Kambris, Z., Cook, P. E., Walker, T., and Sinkins, S. P. (2009). Horizontal gene transfer between Wolbachia and the mosquito Aedes aegypti. BMC Genomics 10:33. doi: 10.1186/1471-216410-33

Koh, A. L., Sun, C. X., Zhu, F., and Glogauer, M. (2005). The role of Rac1 and Rac2 in bacterial killing. Cell. Immunol. 235, 92-97. doi: 10.1016/j.cellimm.2005.07.005

Kondo, N., Nikoh, N., Ijichi, N., Shimada, M., and Fukatsu, T. (2002). Genome fragment of
Wolbachia endosymbiont transferred to $\mathrm{X}$ chromosome of host insect. Proc. Natl. Acad. Sci. U.S.A. 99, 14280-14285. doi: 10.1073/pnas.222228199

Kosaka, N., and Ochiya, T. (2011). Unraveling the mystery of cancer by secretory microRNA: horizontal microRNA transfer between living cells. Front. Genet. 2:97. doi: 10.3389/fgene.2011.00097

Lambertz, U., Silverman, J. M., Nandan, D., McMaster, W. R., Clos, J., Foster, L. J., et al. (2012). Secreted virulence factors and immune evasion in visceral leishmaniasis. J. Leukoc. Biol. 91, 887-899. doi: 10.1189/jlb.0611326

Lamrabet, O., Merhej, V., Pontarotti, P., Raoult, D., and Drancourt, M. (2012). The genealogic tree of mycobacteria reveals a long sympatric life into free-living protozoa. PLoS ONE 7:e34754. doi: 10.1371/journal.pone.0034754

Lemgruber, L., Kudryashev, M., Dekiwadia, S., Riglar, D. T., Baum, J., Stahlberg, H., et al. (2013). Cryo-electron tomography reveals four-membrane architecture of the Plasmodium apicoplast. Malar. J. 12, 25. doi: 10.1186/1475-2875-12-25

Leoratti, F. M., Trevelin, S. C., Cunha, F. Q., Rocha, B. C., Costa, P. A., Gravina, H. D., et al. (2012). Neutrophil paralysis in Plasmodium vivax malaria. PLoS Negl. Trop. Dis. 6:e1710. doi: 10.1371/journal.pntd. 0001710

Letunic, I., and Bork, P. (2011). Interactive Tree Of Life v2: online annotation and display of phylogenetic trees made easy. Nucleic Acids Res. 39(Web Server issue), W475-W478. doi: 10.1093/nar/gkr201

Lew, V. L. (2011). Malaria: surprising mechanism of merozoite egress revealed. Curr. Biol. 21, R314-R316. doi: 10.1016/j.cub.2011.03.066

Li, H., Huang, S., Guo, C., Guan, H., and Xiong, C. (2012). Cell-free seminal mRNA and microRNA exist in different forms. PLoS ONE 7:e34566. doi: 10.1371/journal. pone. 0034566

Liegeois, S., Benedetto, A., Garnier, J. M., Schwab, Y., and Labouesse, M. (2006). The V0-ATPase mediates apical secretion of exosomes containing Hedgehog-related proteins in Caenorhabditis elegans. J. Cell Biol. 173, 949-961. doi 10.1083/jcb.200511072

Ludin, P., Nillson, D., and Maeser, P. (2011). Genome-wide identification of molecular mimicry candidates in 
parasites. PLoS ONE 6:e17546. doi: 10.1371/journal.pone.0017546

Lyke, K. E., Dicko, A., Dabo, A., Sangare, L., Kone, A., Coulibaly, D., et al. (2005). Association of Schistosoma haematobium infection with protection against acute Plasmodium falciparum malaria in Malian children. Am. J. Trop. Med. Hyg. 73, 1124-1130.

Mamuti, W., Sako, Y., Bart, J. M., Nakao, M., Ma, X., Wen, H., et al. (2007). Molecular characterization of a novel gene encoding an $8-\mathrm{kDa}$-subunit of antigen $\mathrm{B}$ from Echinococcus granulosus genotypes 1 and 6. Parasitol. Int. 56, 313-316. doi: 10.1016/j.parint.2007. 06.003

Mantel, P. Y., Hoang, A. N., Goldowitz, I., Potashnikova, D., Hamza, B., Vorobjev, I., et al. (2013). Malaria microvesicles act as messengers that induce potent responses in immune cells and parasites. Cell Host Microbe 13, 521-534. doi: 10.1016/j.chom. 2013.04.009

Manzano-Roman, R., and SilesLucas, M. (2012). MicroRNAs in parasitic diseases: potential for diagnosis and targeting. Mol. Biochem. Parasitol. 186, 81-86. doi: 10.1016/j.molbiopara.2012.10.001

Marcilla, A., Trelis, M., Cortes, A., Sotillo, J., Cantalapiedra, F., Minguez, M. T., et al. (2012). Extracellular vesicles from parasitic helminths contain specific excretory/secretory proteins and are internalized in intestinal host cells. PLoS ONE 7:e45974. doi: 10.1371/ journal.pone.0045974

Martin-Jaular, L., Nakayasu, E. S., Ferrer, M., Almeida, I. C., and del Portillo, H. A. (2011). Exosomes from Plasmodium yoelii-infected reticulocytes protect mice from lethal infections. PLOS ONE 6:e26588. doi: 10.1371/journal. pone. 0026588

McNulty, S. N., Foster, J. M., Mitreva, M., Dunning Hotopp, J. C., Martin, J., Fischer, K., et al. (2010). Endosymbiont DNA in endobacteria-free filarial nematodes indicates ancient horizontal genetic transfer. PLoS ONE 5:e11029. doi: 10.1371/journal.pone.0011029

Moliner, C., Fournier, P. E., and Raoult, D. (2010). Genome analysis of microorganisms living in amoebae reveals a melting pot of evolution. FEMS Microbiol. Rev. 34, 281-294. doi: 10.1111/j.1574-6976. 2009.00209.x

Natakamol, D., Dondorp, A. M., Krudsood, S., Udomsangpetch, R., Pattanapanyasat, K., Combes, V., et al. (2011). Circulating red-cell derived microparticles in human malaria. J. Infect. Dis. 203, 700-706. doi: 10.1093/infdis/jiq104

Nicola, A. M., Frases, S., and Casadevall, A. (2009). Lipophilic dye staining of Cryptococcus neoformans extracellular vesicles and capsule. Eukaryot. Cell 8, 1373-1380. doi: 10.1128/EC.000 44-09

Nielsen, H., Kharazmi, A., and Theander, T. G. (1986). Suppression of blood monocyte and neutrophil chemotaxis in acute human malaria. Parasite Immunol. 8, 541-550. doi: 10.1111/j.13653024.1986.tb00868.x

Nono, J. K., Pletinckx, K., Lutz, M. B., and Brehm, K. (2012). Excretory/secretory-products of Echinococcus multilocularis larvae induce apoptosis and tolerogenic properties in dendritic cells in vitro. PLoS Negl. Trop. Dis. 6:e1516. doi: 10.1371/journal.pntd.0001516

Oliveira, D. L., Freire-de-Lima, C. G., Nosanchuk, J. D., Casadevall, A., Rodrigues, M. L., and Nimrichter, L. (2010). Extracellular vesicles from Cryptococcus neoformans modulate macrophage functions. Infect. Immun. 78, 1601-1609. doi: 10.1128/IAI.01171-09

Ouassi, A., Aguirre, T., PlumasMarty, B., Piras, M., Schoneck, R., Gras-Masse, H., et al. (1992). Cloning and sequencing of a 24$\mathrm{kDa}$ Trypanosoma cruzi specific antigen released in association with membrane vesicles and defined by a monoclonal antibody. Biol. Cell 75, 11-17. doi: 10.1016/0248-4900(92) 90119-L

Panepinto, J., Komperda, K., Frases, S., Park, Y.-D., Djordjevic, J. T., Casadevall, A., et al. (2009). Sec6-dependent sorting of fungal extracellular exosomes and laccase of Cryptococcus neoformans. Mol. Microbiol. 71, 1165-1176. doi: 10.1111/j.1365-2958.2008.06588.x

Papadopoulos, J. S., and Agarwala, R. (2007). COBALT: constraint-based alignment tool for multiple protein sequences. Bioinformatics 23, 1073-1079. doi: 10.1093/bioinformatics/btm076

Petney, T. N., and Andrews, R. H. (1998). Multiparasite communities in animals and humans: frequency, structure and pathogenic significance. Int. J. Parasitol. 28, 377-393. doi: 10.1016/S0020-7519 (97)00189-6

Pierson, T., Matrakas, D., Taylor, Y. U., Manyam, G., Morozov, V. N., Zhou, W., et al. (2011). Proteomic char- acterization and functional analysis of outer membrane vesicles of Francisella novicida suggests possible role in virulence and use as a vaccine. J. Proteome Res. 10 954-967. doi: 10.1021/pr1009756

Pisetsky, D. S., Gauley, J., and Ullal, A. J. (2011). Microparticles as a source of extracellular DNA. Immunol. Res. 49, 227-234. doi: 10.1007/s12026010-8184-8

Pollak, C. N., Delpino, M. V., Fossati, C. A., and Baldi, P. C. (2012). Outer membrane vesicles from Brucella abortus promote bacterial internalization by human monocytes and modulate their innate immune response. PLoS ONE 7:e50214. doi: 10.1371/journal.pone.0050214

Price, C. T., Al-Khodor, S., AlQuanadan, T., Santic, M., Habyarimana, F., Kalia, A., et al. (2009). Molecular mimicry by an F-box effector of Legionella pneumophila hijacks a conserved polyubiqitination machinery within macrophages and Protozoa. PLoS Pathog. 5:e1000704. doi: 10.1371/ journal.ppat.1000704

Price, C. T. D., and Kwaik, Y. A. (2010). Exploitation of host polyubiquitination machinery through molecular mimicry by eukaryotic-like bacterial F-box effectors. Front. Microbiol. 1:122. doi: 10.3389/fmicb.2010. 00122

Quah, B. J., and O'Neill, H. C. (2007). Mycoplasma contaminants present in exosome preparations induce polyclonal B cell responses. J. Leukoc. Biol. 82, 1070-1082. doi: 10.1189/jlb.0507277

Rak, J., and Guha, A. (2012). Extracellular vesicles-vehicles that spread cancer genes. Bioessays 34, 489-497. doi: 10.1002/bies.201 100169

Ramachandra, L., Qu, Y., Wang, Y., Lewis, C. J., Cobb, B. A., Takatsu, K., et al. (2010). Mycobacterium tuberculosis synergizes with ATP to induce release of microvesicles and exosomes containing major histocompatibility complex class II molecules capable of antigen presentation. Infect. Immun. 78, 5116-5125. doi: 10.1128/IAI.010 89-09

Raoult, D., and Boyer, M. (2010). Amoebae as genitors and reservoirs of giant viruses. Intervirology 53 321-329. doi: 10.1159/000312917

Ratajczak, J., Miekus, K., Kucia, M., Zhang, J., Reca, R., Dvorak, P., et al. (2006). Embryonic stem cell-derived microvesicles reprogram hematopoietic progenitors: evidence for horizontal transfer of mRNA and protein delivery. Leukemia 20, 847-856. doi: 10.1038/sj.leu.2404132

Regev-Rudzki, N., Wilson, D. W. Carvalho, T. G., Sisquella, X., Coleman, B. M., Rug, M., et al. (2013). Cell-cell communication between malaria-infected red blood cells via exosome-like vesicles. Cell 153, 1120-1133. doi: 10.1016/j.cell. 2013.04.029

Ricard, G., McEwan, N. R., Dutilh, B. E., Jouany, J. P., Macheboeuf, D., Mitsumori, M., et al. (2006) Horizontal gene transfer from Bacteria to rumen Ciliates indicates adaptation to their anaerobic, carbohydrates-rich environment. BMC Genomics 7:22. doi: 10.1186/ 1471-2164-7-22

Roberts, A. W., Kim, C., Zhen, L., Lowe, J. B., Kapur, R., Petryniak, B., et al. (1999). Deficiency of the hematopoietic cell-specific Rho family GTPase Rac2 is characterized by abnormalities in neutrophil function and host defense. Immunity 10, 183-196. doi: 10.1016/S1074-7613(00)80019-9

Robinson, M. W., Donnelly, S., Hutchinson, A. T., To, J., Taylor, N. L., Norton, R. S., et al. (2011). A family of helminth molecules that modulate innate cell responses via molecular mimicry of host antimicrobial peptides. PLoS Pathog. 7:e1002042. doi: 10.1371/journal. ppat. 1002042

Rodrigues, M. L., Nakayasu, E. S., Oliveira, D. L., Nimrichter, L., Nosanchuk, J. D., Almeida, E. S., et al. (2008). Extracellular vesicles produced by Cryptococcus neoformans contain protein components associated with virulence. Eukaryot. Cell 7, 58-67. doi: 10.1128/EC.003 70-07

Ronquist, G. K., Larsson, A., StavreusEvers, A., and Ronquist, G. (2012). Prostasomes are heterogeneous regarding size and appearance but affiliated to one DNA-containing exosome-family. Prostate 72, 1736-1745. doi: 10.1002/pros.22526

Ronquist, K. G., Ronquist, G., Carlsson, L., and Larsson, A. (2009). Human prostasomes contain chromosomal DNA. Prostate 69, 737-743. doi: 10.1002/pros.20921

Selman, M., and Corradi, N. (2011). Microsporidia: horizontal gene transfer in the vicious parasites. Mob. Genet. Elements 1, 251-255. doi: 10.4161/mge.18611

Semenov, D. V., Baryakin, D. N., Brenner, E. V., Kurilshikov, A. M., Vasiliev, G. V., Bryzgalov, L. A., et al. (2012). Unbiased 
approach to profile the variety of small non-coding RNA of human blood plasma with massively parallel sequencing technology. Expert Opin. Biol. Ther. (Suppl. 1), S43-S51. doi: 10.1517/14712598. 2012.679653

Sepulveda, P., Liegeard, P., Wallukat, G., Levin, M. J., and Hontebeyrie, M. (2000). Modulation of cardiocyte functional activity by antibodies against Trypanosoma cruzi Ribosomal P2 protein C terminus. Infect. Immun. 68, 5114-5119. doi: 10.1128/IAI.68.9. 5114-5119.2000

Silverman, J. M., Clos, J., de'Oliveira, C. C., Shirvani, O., Fang, Y., Wang, C., et al. (2010a). An exosome-based secretion pathway is responsible for protein export from Leishmania and communication with macrophages. J. Cell Sci. 123, 842-852. doi: $10.1242 /$ jcs. 05 6465

Silverman, J. M., Clos, J., Horakova, E., Wang, A. Y., Wiesgigl, M., Kelly, I., et al. (2010b). Leishmania exosomes modulate innate and adaptive immune responses through effects on monocytes and dendritic cells. J. Immunol. 185, 5011-5022. doi: 10.4049/jimmunol.1000541

Silverman, J. M., and Reiner, N. E. (2011). Exosomes and other microvesicles in infection biology: organelles with unanticipated phenotypes. Cell. Microbiol. 13, 1-9. doi: 10.1111/j.1462-5822.2010. 01537.x

Silverman, J. M., and Reiner, N. E. (2012). Leishmania exosomes deliver preemptive strikes to create an environment permissive for early infection. Front. Cell. Infect. Microbiol. 1:26. doi: 10.3389/fcimb. 2011.00026

Singh, P. P., LeMaire, C., Tan, J. C., Zeng, E., and Schorey, J. S. (2011). Exosomes released from $M$. tuberculosis infected cells can suppress IFN-gamma mediated activation of naive macrophages. PLOS ONE 6:e18564. doi: 10.1371/journal. pone. 0018564

Singh, P. P., Smith, V. L., Karakousis, P. C., and Schorey, J. S. (2012). Exosomes isolated from mycobacteria-infected mice or cultured macrophages can recruit and activate immune cells in vitro and in vivo. J. Immunol. 189, 777-785. doi: 10.4049/jimmunol. 1103638

Skog, J., Wuerdinger, T., van Rijn, S., Meijer, D. H., Gainche, L., Sena-Esteves, M., et al. (2008). Glioblastoma microvesicles transport RNA and proteins that promote tumour growth and provide diagnostic biomarkers. Nat. Cell Biol. 10, 1470-1476. doi: 10.1038/ncb1800

Sotillo, J., Valero, M., Sanchez del Pino, M. M., Fried, B., Esteban, J. G., Marcilla, A., et al. (2010). Excretory/ secretory proteome of the adult stage of Echinostoma caproni. Parasitol. Res. 107, 691-697. doi: 10.1007/s00436-0101923-x

Spolski, R. J., Corson, J., Thomas, P. G., and Kuhn, R. E. (2000). Parasite-secreted products regulate the host response to larval Taenia crassiceps. Parasite Immunol. 22, 297-305. doi: 10.1046/j.1365-3024. 2000.00301.x

Telfer, S., Lambin, X., Birtles, R., Beldomenico, P., Burthe, S., Paterson, S., et al. (2010). Species interactions in a parasite community drive infection risk in a wildlife population. Science 330 , 243-246. doi: 10.1126/science.119 0333

Toledo, A., Coleman, J. L., Crowley, J. T., and Benach, J. L. (2012). The enolase of Borrelia burgdoferi is a plasminogen receptor released in outer membrane vesicles. Infect. Immun. 80, 359-368. doi: 10.1128/IAI.05836-11

Torrecilhas, A. C., Schimacher, R. I., Alves, M. J., and Colli, W. (2012). Vesicles as carriers of virulence factors in parasitic protozoan diseases. Microb. Infect. 14, 1465-1474. doi: 10.1016/j.micinf 2012.07.008

Trelka, D. P., Schneider, T. G., Reeder, J. C., and Tarashi, T. F. (2000). Evidence for vesicle-mediated trafficking of parasite proteins to the host cytosol and erythrocyte surface membrane in Plasmodium falciparum infected erythrocytes. Mol. Biochem. Parasitol. 196, 131-145. doi: 10.1016/S0166-6851 (99)00207-8

Trocoli Torrecilhas, A. C., Tonelli, R. R., Pavanelli, W. R., da Silva, J. S., Schumacher, R. I., de Souza, W., et al. (2009). Trypanosoma cruzi: parasite shed vesicles increase heart parasitism and generate an intense inflammatory response. Microbes Infect. 11, 29-39. doi: 10.1016/j.micinf.2008. 10.003

Valadi, H., Ekstrom, K., Bossios, A., Sjostrand, M., Lee, J. J., and Loetvall, J. O. (2007). Exosomemediated transfer of mRNAs and microRNAs is a novel mechanism of genetic exchange between cells. Nat. Cell Biol. 9, 654-659. doi: 10.1038/ncb1596
Vallejo, M. C., Matsuo, A. L., Ganiko, L., Soares Medeiros, L. C., Miranda, K., Silva, L. S., et al. (2011). The pathogenic fungus Paracoccidioides brasiliensis exports extracellular vesicles containing highly immunogenic alpha-galactosyl epitopes. Eukaryot. Cell 10, 343. doi: 10.1128/EC.00227-10

Vallejo, M. C., Nakayasu, E. S., Longo, L. V. G., Ganiko, L., Lopes, F. G., Matsuo, A. L., et al. (2012a). Lipidomic analysis of extracellular vesicles from the pathogenic phase of Paracoccidioides brasiliensis. PLoS ONE 7:e39463. doi: 10.1371/journal.pone. 0039463

Vallejo, M. C., Nakayasu, E. S., Matsuo, A. L., Sobreira, T. J. P., Longo, L. V. G., Ganiko, L., et al. (2012b). Vesicle and vesicle-free extracellular proteome of Paracoccidioides brasiliensis: comparative analysis with other pathogenic fungi. J. Proteome Res. 11, 1676-1685. doi $10.1021 / \mathrm{pr} 200872 \mathrm{~s}$

Vickers, K. C., and Remaley, A. T. (2012). Lipid-based carriers of microRNAs and intracellular communication. Curr. Opin. Lipidol. 23, 91-97. doi: 10.1097/MOL.0b013e328350a425

Waldenstroem, A., Gennebaeck, M. Hellman, G., and Ronquist, G. (2012). Cardiomyocytes microvesicles contain DNA/RNA and convey biological messages to target cells. PLOS ONE 7:e34653. doi: 10.1371/journal. pone. 0034653

Walker, M., Baz, A., Dematteis, S., Stettler, M., Gottstein, B., Schaller, J., et al. (2004). Isolation and characterization of a secretory component of Echinococcus multiocularis metacestodes potentially involved in modulating the hostparasite interface. Infect. Immun. 71, 527-536. doi: 10.1128/IAI.72.1.527536.2004

Wang, K., Li, H., Yuan, Y., Etheridge, A., Zhou, Y., Huang, D., et al. (2012) The complex exogenous RNA spectra in human plasma: an interface with human gut biota. PLoS ONE 7:e51009. doi: 10.1371/journal.pone.0051009

Wayengera, M. (2009). Searching for new clues about the molecular cause of endomyocardial fibrosis by way of silico proteomics and analytical chemistry. PLoS ONE 4:e7420. doi: 10.1371/journal.pone. 0007420

Weber, S. S., Parente, A. F. A., Borges, C. L., Parente, J. A., Bailao, A. M., and de Almeida Soares, C. M. (2012). Analysis of the secretomes of Paracoccidioides mycelia and yeast cells. PLoS ONE 7:e52470. doi: 10.1371/journal.pone.0052470

Weiss, B., and Aksoy, S. (2011). Microbiome influences on insect host vector competence. Trends Parasitol. 27, 514-522. doi: 10.1016/j.pt.2011.05.001

Werren, J. H., Baldo, L., and Clark, M. E. (2008). Wolbachia: master manipulators of invertebrate biology. Nat. Rev. Microbiol. 6, 741-751. doi: 10.1038/nrmicro1969

Wilson, R. A., Wright, J. M., de Castro-Borges, W., Parker-Manuel, S. J., Dowle, A. A., Ashton, P. D., et al. (2011). Exploring the Fasciola Hepatica tegument proteome. Int. J. Parasitol. 41, 1347-1359. doi: 10.1016/j.ijpara. 2011.08.003

Woolfit, M., Iturbe-Ormaetxe, I., McGraw, E. A., and O'Neill, S. L. (2009). An ancient horizontal gene transfer between mosquito and the endosymbiotic bacterium Wolbachia pipientis. Mol. Biol. Evol. 26, 367-374. doi: 10.1093/molbev/msn253

Xu, L., Yang, B. F., and Ai, J. (2013). MicroRNA transport: a new way in cell communication. J. Cell. Physiol. 228, 1713-1719. doi: $10.1002 /$ jcp. 24344

Yamauchi, A., Marchal, C. C., Molitoris, J., Pech, N., Knaus, U., Towe, J., et al. (2005). Rac GTPase isoform-specific regulation of NADPH oxidase and chemotaxis in murine neutrophils in vivo. Role of C-terminal polybasic domain. J. Biol. Chem. 280, 953-964. doi: 10.1074/jbc.M408820200

Yang, C., Chalasani, G., Ng, Y. H., and Robbins, P. D. (2012). Exosomes released from Mycoplasma infected tumor cells activate inhibitory B cells. PLoS ONE 7:e36138. doi: 10.1371/journal.pone.0036138

Yoneda, A., and Doering, T. L. (2006) A eukaryotic capsular polysaccharide is synthesized intracellularly and secreted via exocytosis. Mol. Biol. Cell 17, 5131-5140. doi: 10.1091/mbc.E06-08-0701

Yoon, H., Ansong, C., Adkins, J. N., and Heffron, F. (2011). Discovery of Salmonella virulence factors translocated via outer membrane vesicles to murine macrophages. Infect. Immun. 79, 2182-2192. doi: 10.1128/IAI.01277-10

Zaccone, P., and Cooke, A. (2013). Vaccine against autoimmune disease: can helminths or their products provide a therapy. Curr. Opin. Immunol. 25, 418-423. doi: 10.1016/j.coi.2013.02.006

Zhang, H., Sun, C., Glogauer, M., and Bokoch, G. M. (2009). Human 
neutrophils coordinate chemotaxis by differential activation of Rac1 and Rac2. J. Immunol. 183, 2718-2728. doi: 10.4049/jimmunol. 0900849

Zhang, L., Hou, D., Chen, X., Li, D., Zhu, L., Zhang, Y., et al. (2012). Exogenous plant mir168a specifically targets mammalian LDLRAP1: evidence of cross-kingdom regulation by microRNA. Cell Res. 22, 107-126. doi: 10.1038/cr.2011.158

Zhang, Y., Liu, D., Chen, X., Li, J., Li, L., Bian, Z., et al. (2010a). Secreted monocytic miR-150 enhances targeted endothelial cell migration. Mol. Cell 39, 133-144. doi: 10.1016/j.molcel.2010.06.010

Zhang, W., Li, J., Jones, M. K., Zhang, Z., Zhao, L., Blair, D., et al. (2010b) The Echinococcus granulosus antigen $\mathrm{B}$ gene family comprises at least 10 unique genes in five subclasses which are differentially expressed. PLoS Negl. Trop. Dis. 4:e784. doi: 10.1371/journal.pntd. 0000784

Zhong, G. (2011). Chlamydia secretion of proteases for manipulating host signaling pathways. Front. Microbiol. 2:14. doi: 10.3389/fmicb. 2011.00014
Conflict of Interest Statement: The authors declare that the research was conducted in the absence of any commercial or financial relationships that could be construed as a potential conflict of interest.

Received: 17 June 2013; accepted: 20 August 2013; published online: 06 September 2013.

Citation: Barteneva NS, Maltsev N and Vorobjev IA (2013) Microvesicles and intercellular communication in the context of parasitism. Front. Cell. Infect. Microbiol. 3:49. doi: 10.3389/fcimb. 2013.00049
This article was submitted to the journal Frontiers in Cellular and Infection Microbiology.

Copyright (C) 2013 Barteneva, Maltsev and Vorobjev. This is an open-access article distributed under the terms of the Creative Commons Attribution License (CC BY). The use, distribution or reproduction in other forums is permitted, provided the original author(s) or licensor are credited and that the original publication in this journal is cited, in accordance with accepted academic practice. No use, distribution or reproduction is permitted which does not comply with these terms. 